\title{
Erratum to: Electrochemical and nanogravimetric studies of poly(copper phthalocyanine) microparticles immobilized on gold in aqueous solutions
}

\author{
Katalin Borsos $^{1}$ • György Inzelt ${ }^{1}$
}

Published online: 10 June 2015

(C) Springer-Verlag Berlin Heidelberg 2015

\section{Erratum to: J Solid State Electrochem}

DOI 10.1007/s10008-015-2770-6

The original version of the article, unfortunately, contained a mistake in the caption of Fig. 2. The correct numbering of the curves on Fig. 2, i.e., the correct figure caption is as follows.

Fig. 2 Cyclic voltammetric (a) and the simultaneously obtained EQCN frequency (b) responses for an $\mathrm{Au} \mid$ poly $(\mathrm{CuPc})$ electrode in contact with electrolyte solutions of different $\mathrm{pH}$ values at constant $1 \mathrm{~mol} \mathrm{dm}^{-3}$ ionic strength: $0.001 \mathrm{~mol} \mathrm{dm}^{-3}$ perchloric acid $+0.999 \mathrm{~mol} \mathrm{dm}^{-3} \mathrm{NaClO}_{4}(1), 0.01 \mathrm{~mol} \mathrm{dm}^{-3}$ perchloric acid $+0.99 \mathrm{~mol} \mathrm{dm}^{-3} \mathrm{NaClO}_{4}$ (2), $0.1 \mathrm{~mol} \mathrm{dm}^{-3}$ perchloric acid $+0.9 \mathrm{~mol} \mathrm{dm}^{-3} \mathrm{NaClO}_{4}(3)$, and $1 \mathrm{~mol} \mathrm{dm}^{-3}$ perchloric acid (4). Scan rate: $20 \mathrm{mV} \mathrm{s}^{-1}$

The online version of the original article can be found at http://dx.doi.org/ 10.1007/s10008-015-2770-6.

György Inzelt

inzeltgy@chem.elte.hu

1 Department of Physical Chemistry, Institute of Chemistry, Eötvös Loránd University, Pázmány Péter sétány 1/A,

1117 Budapest, Hungary 